\section{Intrinsic Factor}

SIR,-We appreciated Dr. S. Padmanabh's interesting views (28 May, p. 1357) on our recent article (7 May, p. 1149) and would like to reply briefly to them. His first comment-that the controversy should be about the nature and action of intrinsic factorperplexes us. Surely there is no controversy about the action of intrinsic factor-all workers in this field agree that intrinsic factor facilitates the absorption of $B_{12}$ by specifically binding with the crystalline form of the vitamin in the stomach. Concerning the nature of intrinsic factor-that controversy had better be left to those who believe in its existence. We hope, too, that we have defined the action of cobalamase sufficiently clearly to distinguish it from that of intrinsic factor $^{1}$ and to show that the only thing common to both the intrinsic factor and cobalamase theories is agreement that the defect in pernicious anaemia lies primarily in the gastric secretion. Evidence of this has existed for nearly 100 years. $^{2}$ To infer from this one common factor, however, that "intrinsic factor" and "cobalamase" are identical is similar to claiming that " black" is "white" because both are colours. It is debasement of both terms and is fair to neither theory.

In his second paragraph Dr. Padmanabh's defence of intrinsic factor appears essentially to rest upon the antigen-antibody reactions between gastric juice, pernicious anaemia serum, and crystalline vitamin $\mathrm{B}_{12}$, which are currently being reported. Over two years ago we asked three basic questions on this topic. $^{3} \quad$ Two were ignored completely ${ }^{4}$ and the third was answered in what can best be described as a perplexing way. ${ }^{\circ}$ If $\mathrm{Dr}$. Padmanabh-or anyone else-cares to reply to the two unanswered questions we shall be grateful. The first is how can "antibodies" to intrinsic factor be recognized, bearing in mind that the "antigen" with which they are presumed to react specifically remains unisolated, unidentified, and unknown? The second is, do experiments using crystalline vitamin $\mathrm{B}_{12}$ and gastric juice have physiological value? If so, then how is crystalline $B_{12}$ detached from its native conjugates prior to its combination with intrinsic factor?

All we can add concerning these antigenantibody reactions is we believe that we are in danger of becoming so bemused by them that it is now accepted, without demur, that a patient with a normal marrow and blood film, a serum $B_{12}$ level of $360 \mu \mu \mathrm{g} . / \mathrm{ml}$. and a haemoglobin content of $115 \%$, and who also may never present symptoms of anaemia to his dying day is nevertheless suffering from latent pernicious anaemia. ${ }^{6} \mathrm{He}$ may, we suppose, be suffering also from latent leropsy.

In his penultimate paragraph, having agreed that serum $B_{12}$ levels probably do not reflect tissue saturation, Dr. Padmanabh nevertheless warns us that serum levels of patients on intrinsic factor or preparations tend to be higher, at least for three years, than those treated with $B_{12}$ peptide complexes. We are glad to hear this, for we already have some evidence that the $B_{12}$ peptides probably leave the serum more quickly than corresponding intrinsic factor preparations, to be either utilized immediately or stored in the liver.

In his last paragraph Dr. Padmanabh proposes that such a thing as "intrinsic factor activity" exists. If by that he means that mixtures of crystalline $\mathrm{B}_{12}$ and some protein(s) facilitate(s) absorption of the vitamin, then we agree with him. There is a vast amount of published work to support this. Whether this is the physiological way, however, by which the natural vitamin-that is, the protein-bound form-is absorbed, is quite a different story. Considering that usually over $50 \%$ patients treated with "purified" intrinsic-factor- $B_{12}$ mixtures develop resistance within 18 months of the commencement of treatment, we believe that this is an abnormal method of $\mathrm{B}_{12}$ absorption.

Finally, Dr. Padmanabh introduces yet another "remotely possible" action of intrinsic factor. How very depressing. $\mathrm{He}$ considers that it may "prevent recombination of released $B_{12}$ with other proteins once it has been split off from the combined state." But how is the splitting off first achieved ? Is it brought about by "cobalamase"? After all, we have postulated the cobalamase initiates such an action. If it is " cobalamase," then presumably Dr. Padmanabh would prefer it to be called "intrinsic factor." But " intrinsic factor" by universal definition is alleged to combine with $\mathrm{B}_{12}$, and not to prevent its combination. Perhaps it does both at the same time? Perhaps, like Humpty Dumpty in Through the Looking Glass, Dr. Padmanabh considers the term intrinsic factor "means just what I choose it to mean-neither more nor less." Alice's reply is apposite: "The question is," she says, "whether you can make words mean different things."

For ourselves we believe simply that pernicious anaemia is caused by lack of a specific endopeptidase, cobalamase. This appears to be far simpler than believing in "intrinsic factor," which appears to involve standing on one's head and feet at the same time, while declaring " black" is "white." We are, etc.

\section{St. Helens Hospital, J. G. HEATHCoTe.}

\section{RBPERENCBS}

1 Mooney, F. S., and Heathcote, J. G., Brit. med. F., 1966, 1, 1149

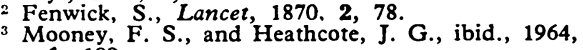
$1,109$.
Ardeman, S., and Chanarin, I., ibid., 1964, 1, 384.

Mooney, F. S., and Heathcote, J. G., ibid., 1964, Wangel, A. G., and Schiller, K. F. R., Brit. med. f., 1966, 1, 1274 .

SIR,-In their paper (7 May, p. 1149) Dr. F. S. Mooney and Dr. J. G. Heathcote make two allegations contrary to fact.

The first is " that the vitamin- $\mathrm{B}_{12}$-peptide complexes are much more effective than crystalline vitamin $\mathrm{B}_{12}$ alone in the oral treatment of pernicious anaemia." This claim has been correctly attacked as invalid by a number of competent investigators on the ground that the clinical results obtained from the complex can be obtained from the vitamin- $B_{12}$ content alone. ${ }^{1-9}$

The second statement contrary to fact is "that the reason why intrinsic factor has not yet been isolated is simply that it does not exist." In fact, intrinsic factor has been isolated. Highley and Ellenbogen have isolated hog intrinsic factor ${ }^{10} 11$ and Gräsbeck, Simons, and Sinkkonen ${ }^{13}$ have isolated human intrinsic factor. It is a glycoprotein dimer with a molecular weight in the range of 100,000.-I am, etc.,

Mount Sinai Hospital, VICTOR HeRberT.
New York.

\section{REFERENCES}

1 Latner, A. L., Lancet, 1958, 1, 1077

Castle, W. B., ibid., 1958, $2,270$.

Herbert, V., E., Estren, 1958, 2, 747 , Brody, E., and

Wasserman,' L. R., ibid.,' 1958,2, , $^{2} 801$.

Formine, P., ibid.,' 1958, 2, 1017.

Chalmers, J., N. M., and Shinton, N. K., ibid., $1958,2,1069$.

Hausmann, K., and Mulli, K., ibid., 1959, 1, 889

Ellenbogen, L., Newer Methods of Nutritional Biochemistry, ed. A. A. Albanese, 1963. New York.

Glass, G. B. J., Physiol. Rev., 1963, 43, 529. Highley, D. R., and Ellenbogen, L., Fed. Proc., $\frac{1965,24,421}{\text { Davies, }} M$. C., and Ellenbogen, L., ibid., $1966,25,277$.

Gräsbeck, R., Simons, K., and Sinkkonen, I., Acta chem. scand., 1965, 19, 1777.

\section{"Coin Test" for Cutaneous Sensibility}

SIR,-A story is getting round that I invented the "coin test" for cutaneous sensibility. I have had letters about it, and it is referred to by Dr. Lars önne in Current Practice in Orthopaedic Surgery, 1964, Vol. 2, page 46: "Coin test. In this test, which was introduced by Seddon (unpublished), the skin is stroked with a smooth and a milled coin in turn. It is possible to examine small areas of skin in this way. This test is capricious because it seems impossible to prevent the milled coin from producing small vibrations which are transmitted to normally innervated tissue."

I first saw this test demonstrated by Brigadier George Riddoch early in the last war; I don't think he invented it, but perhaps because he was an Aberdonian it made a great appeal to him. Maybe one of our senior neurologists can throw light on its origin.

It is a test, and a practical one, of tactile discrimination in the hand, applicable to patients with median, or median and ulnar nerve lesions. The patient, who closes his eyes or looks elsewhere, is given a coin and asked to identify it. If the sensory disturbance is limited to the median area he must not cheat by wriggling the coin over towards his normal little finger. Of course, unlike two-point discrimination, it is not quantitative but it has to do with daily needs, as when using a public telephone or buying a bus ticket.

Dr. Önne has not been in touch with me about this test nor has he answered a letter I sent him. I have never used the coin test or seen it used in the way he describes, and his criticism of it is therefore invalid.-I am, etc.,

The Institute of Orthopaedics,
London W.1.

H. J. SEDDON.

\section{Salivary Gland Enlargement and Phenylbutazone}

SIR,-I was most interested in the case of salivary gland enlargement and phenylbutazone reported by Drs. L. Cohen and $P$. Banks (4 June, p. 1420). The following patient, who is attending the rheumatology department of this hospital, has a similar history but with several important differences. 
A 44-year-old ship steward developed acute gout in 1962, which was treated with intramuscular phenylbutazone (Butazolodin). He then developed symmetrical enlargement of the parotid salivary glands. This lasted for about one month, during which time the dose of phenylbutazone was reduced and given orally, and subsequently replaced by sulphinpyrazone (Anturan). The patient did not attend further follow-up appointments, but he reappeared in November 1965 with a recurrence of the parotid gland swellings and painful joints, especially the metatarsophalangeal joint of the right big toe. He told us that he had an acute attack of gout while at sea eight months previously, when the parotid glands had swollen. He had taken large doses of phenylbutazone for a few days, but while the joint pains had temporarily resolved the parotid glands had remained enlarged. He had continued to take small doses of phenylbutazone at irregular intervals. There was no evidence of sarcoidosis; his lachrymal glands were not enlarged. The serum uric acid was $9.6 \mathrm{mg} . / 100 \mathrm{ml}$. ; a sialogram was normal. $\mathrm{His}$ joint pains cleared on indomethacin (Indocid) and he was started on probenecid (Benemid), although he does not take this drug regularly, and his serum uric acid has remained raised. The parotid glands remain enlarged but do not worry him.

A summary of the International Congress of Rheumatology held at Mar Del Plata, Argentina, in December 1965, quotes Dr. Goobar, of Coidoba, Argentina, as saying that $80 \%$ of patients with gout that he had observed had painless bilateral swelling of the parotid gland. No mention was made whether any of these cases had received phenylbutazone.

In the outpatients' clinic of this department I have seen no other cases of parotid or submandibular gland enlargement in gout or following phenylbutazone therapy. The case described by Drs. Cohen and Banks mentioned that the phenylbutazone was prescribed for "tennis elbow," and it is interesting to postulate whether this might have been a presenting symptom of gout.

The problem still unsolved is whether the parotid gland swelling follows phenylbutazone therapy or occurs in acute gout irrespective of phenylbutazone therapy, or whether all three factors are related.-I am, etc.,

St. Stephen's Hospital,

D. J. MURray-Bruce.

London S.W.10.

\section{Vaginal Cytology Service}

Sir,-Dr. R. A. McInroy (11 June, p. 1472) makes very clear the great value of a well-organized screening service for vaginal cytology and the considerable advantage to be obtained from centralizing the laboratory side of the service. But I would question his proposed establishment for a central cytological laboratory of one chief technician (Grade Chief II) and four or more technicians (Grade Chief I). For comparison the Ministry regulations permit one chief technician (in Grade I not II) for a general laboratory employing up to 20 technicians and students, and such a laboratory might have six technicians in the Grade Senior II. Dr. McInroy comments that experience and accuracy are fundamental requirements in the staff of a cytological laboratory. I would add that these qualities applied in this context will save lives; this same comment can be made with equal force concerning the senior tech- nicians working in the blood transfusion, histological, biochemical, and bacteriology divisions of a general laboratory. It would be an invidious policy to suggest by a higher salary grading that the technicians in a cytological laboratory do more valuable work and require greater skill than their colleagues elsewhere ; just as it would be unfair to say that, because this is a narrow field, the technicians, once they have acquired experience, will have an easier time. If the purpose of Dr. McInroy's establishment is simply to attract technicians into a new and important service, the result would then be robbing Peter to pay Paul.-I am, etc.,

\section{Friarage Hospital, \\ Northallerton, Yorkshire.}

\section{Unusual Pharyngeal Tumour}

SIR,-An African male patient, about 30 years old, was admitted on 26 August 1964. He had experienced increasing discomfort in his throat for two years. More recently considerable difficulty in swallowing had occurred, and the character of his speech had altered during the last three months. Though able to swallow liquids he was unable to negotiate solid food, and consequently he had lost a considerable amount of weight.

On examination he showed very marked signs of cachexia and general debility. He spoke with difficulty and as if he had a very large "marble" in the back of his throat. He had bouts of difficulty in breathing mainly initiated by the ingestion of his liquid diet.

An $x$-ray of the cervical region revealed a large oval well-demarcated lesion in the pharynx, apparently entirely surrounded by air (Fig.).

A digital examination of the pharynx was carried out under general anaesthesia (nitrous oxide, oxygen, and halothane). The epiglottis was invisible on laryngoscopy and there was no space through which an endotracheal tube of the smallest dimension could be introduced. A firm fleshy tumour with rounded contours was found flattening and at the same time pushing the uvula upwards and slightly forwards. The tumour was of such a size that it was quite impossible to palpate its more distant edges or determine its extent or attachments. Its nature was not recognized.

On 1 September 1964 a tracheostomy was carried out under local anaesthesia. This was followed by induction of general anaesthesia (thiopentone, nitrous oxide, oxygen, and halothane). An incision was made over the upper two-thirds of the anterior border of the left sterno-mastoid muscle. The lower end of the incision was carried medially across the thyroid cartilage to the midline. A large pharyngotomy was performed to expose a large mobile firm tumour attached by a narrow pedicle to the mucosa of the posterior part of the floor of the left nostril. This was in fact a giant nasal polyp. With some difficulty the pedicle was clamped, divided, and ligated, and the tumour removed. The pharynx was then closed in two layers.

The tumour measured $15 \mathrm{~cm}$. by $7.5 \mathrm{~cm}$ by $5 \mathrm{~cm}$. ( 6 in. by 3 in. by 2 in.) and weighed 241 g. $(8.5$ oz.). There was no histological evidence of malignancy.

Following tracheostomy irregularities of respiration were noticed. Therefore controlled respiration with a muscle relaxant was carried out throughout the operation. Only $15 \mathrm{mg}$. of D-tubocurarine was required during two hours of anaesthesia.

At the end of the operation the bloodpressure and the pulse rate were within normal limits, although the respiratory rate was only five per minute. The pattern of respiration was noticed and the presence of periodic breathing was confirmed. The maximum duration of apnoea during one cycle was 45 seconds, which came down to 15 seconds after assisted breathing with a mixture of $5 \%$ carbon dioxide in oxygen intermittently for half an hour. The respiratory rate increased to eight per minute. The patient was then
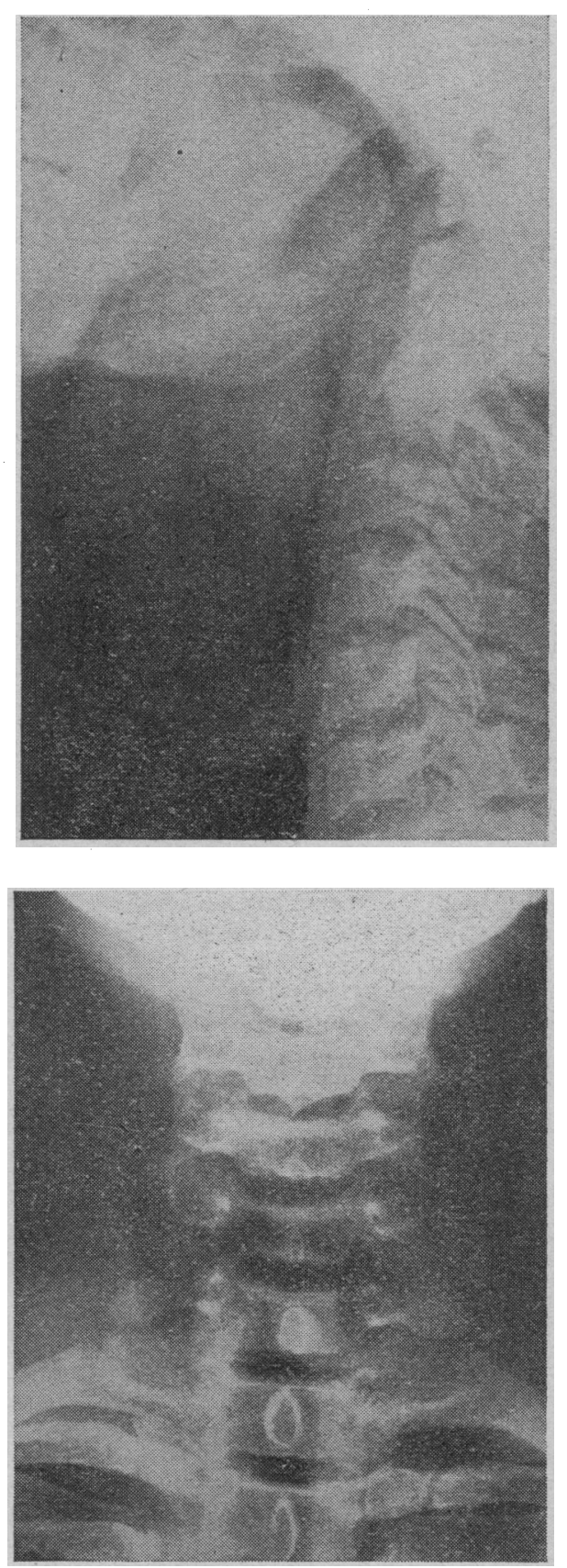

allowed to breathe atmospheric air. Following that the patient's recovery was uneventful. The tracheostomy tube was removed after 72 hours.

From the surgical point of view the main interest in this case lies in the difficulty of pre-operative diagnosis. Nasal polypi of this size are most unusual, and their origin may well not be recognized. If suspected preoperatively, it would be a distinct advantage to open the pharynx at a high level, making the ligation of the pedicle simpler and removal of the entire polyp a straightforward 